\title{
Offspring and adult chemosensory recognition by an amphisbaenian reptile may allow maintaining familiar links in the fossorial environment
}

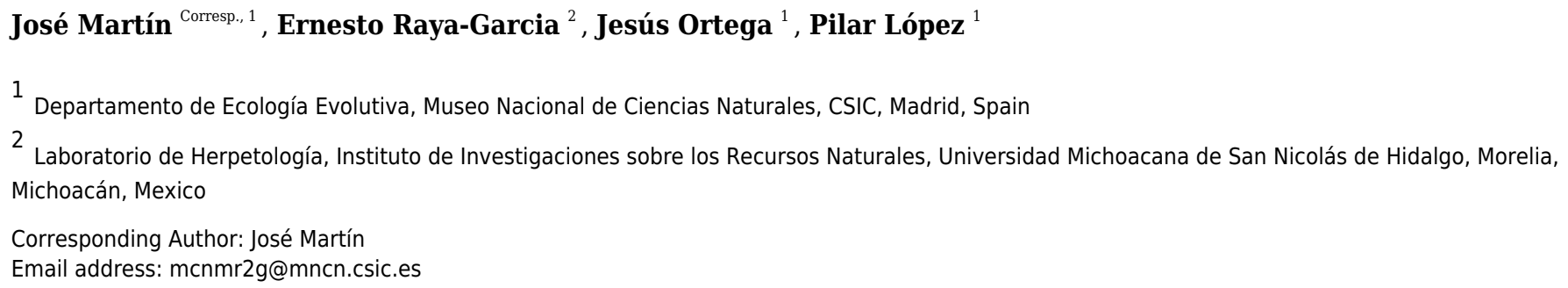

Kin recognition is a phenomenon with an important function in maintaining cohesive social groups in animals. Several studies have examined parent-offspring recognition in species with direct parental care. However, few studies have explored parent-offspring recognition in animals that, at best, only show apparent indirect parental care, such as some reptiles. In this study, we investigated reciprocal parent-offspring recognition in the fossorial amphisbaenian Trogonophis wiegmanni, a viviparous species that shows apparently stable "family groups" in form of parent-offspring long-term associations. We examined whether adult males and females could discriminate via chemical cues between familiar juveniles that live associated with them in their family groups (likely their offspring) and unfamiliar unrelated juveniles, and whether juveniles could discriminate between familiar adult males and females of their family group (likely their parents) and unfamiliar unrelated adults. We measured tongue flick behaviour to study chemosensory responses to scent of conspecifics. We found that adult female amphisbaenians, but not males, could discriminate between scents of familiar and unfamiliar juveniles. Juvenile amphisbaenians did not discriminate between familiar and unfamiliar adult females, but recognize familiar from unfamiliar males. We discuss our results of parent-offspring recognition according to its potential social function in an ecological fossorial context where visibility is limited and chemosensory kin recognition may contribute to the establishment of stable family groups. 
1 Offspring and adult chemosensory recognition by an

2 amphisbaenian reptile may allow maintaining familiar

\section{3 links in the fossorial environment}

5 Jose Martín ${ }^{1}$, Ernesto Raya García ${ }^{2}$, Jesús Ortega ${ }^{1}$ and Pilar López ${ }^{1}$

6

$7{ }^{1}$ Departamento de Ecología Evolutiva, Museo Nacional de Ciencias Naturales, CSIC, Madrid,

$8 \quad$ Spain

$9{ }^{2}$ Laboratorio de Herpetología, Instituto de Investigaciones sobre los Recursos Naturales,

10 Universidad Michoacana de San Nicolás de Hidalgo, Morelia, Michoacán, México

13 Corresponding Author:

14 José Martín

15 Departamento de Ecología Evolutiva, Museo Nacional de Ciencias Naturales, C. José Gutiérrez

16 Abascal 2, 28006 Madrid, Spain

17 Email address: Jose.Martin@mncn.csic.es 


\section{ABSTRACT}

Kin-recognition is a phenomenon with an important function in maintaining cohesive social groups in animals. Several studies have examined parent-offspring recognition in species with direct parental care. Few studies have, however, explored parent-offspring recognition in animals that, at best, only show apparent indirect parental care, such as some reptiles. In this study, we investigated reciprocal parent-offspring recognition in the fossorial amphisbaenian Trogonophis wiegmanni, a viviparous species that shows potential stable 'family groups' in the form of parent-offspring long-term associations. We examined whether adult males and females could discriminate via chemical cues between familiar juveniles which associate with them within groups, and are potentially their offspring, to that of unfamiliar juveniles, and whether juveniles could discriminate between familiar adult males and females of their group (possibly their parents) and unfamiliar unrelated adults. We measured tongue flick behaviour to study chemosensory responses to the scent of conspecifics. We found that adult female amphisbaenians, but not males, could discriminate between scents of familiar and unfamiliar juveniles. Juvenile amphisbaenians did not discriminate between familiar and unfamiliar adult females, but recognize familiar from unfamiliar males. We discuss our results of parentoffspring recognition according to its potential social function in an ecological fossorial context where visibility is limited and chemosensory kin-recognition may contribute to the establishment of stable family groups. 


\section{INTRODUCTION}

40 In social species that present parental care or form family groups, the ability to recognise their own offspring or their own parents and siblings (i.e., kin-recognition) is crucial to maintain longterm stable family associations (Clutton-Brock, 1991; Halpin, 1991; Tang-Martinez, 2001). Although social and family aggregations are widespread in many animals, this is not the case in reptiles, which only rarely show parental care or stable parent-offspring association and social groups (reviewed in Gardner et al., 2016; Whiting \& While 2017; While at al., 2019), yet viviparity seems to be an important factor in the evolution of sociality in reptiles (Halliwell et al., 2017). Cohesive family groups, frequently stable for several seasons, has been previously seen to occur in a few species of viviparous skinks (Bull \& Baghurst, 1998; Duffield \& Bull, 2002; Chapple, 2003; O'Connor \& Shine, 2004; Langkilde, O'Connor \& Shine, 2003; Gardner et al., 2016). An increased understanding of the diversity of social life in reptiles prompts deeper questions about the existence and characteristics of recognition mechanisms by which groups are maintained. For example, mother-offspring and between group member recognition has been found in Egernia-clade skinks (Bull et al., 1994; Main \& Bull, 1996; Bull et al., 2000; O'Connor \& Shine, 2006), but also in some viviparous lizard species without parental care, such as common lizards (Lacerta vivipara; Lena \& de Fraipont, 1998). Sibling recognition has been described in juvenile tree skinks Egernia striolata (Bull et al., 2001) and in hatchling green iguanas (Werner et al., 1987). Conspecific- and kin-recognition in lizards is often mainly based on chemical cues (Bull et al., 2000; reviewed in Mason \& Parker, 2010; Martín \& López, 2011), although in most of these studies the use of additional cues was not discounted. Amphisbaenians are a major distinctive group of fossorial reptile (Gans, 1978, 2005), however, there is very limited information on their social behavior and ecology; likely because 
62 their underground life provides a host of research challenges (Henderson et al., 2016). The

amphisbaenian Trogonophis wiegmanni is a NW African Mediterranean species found from

Morocco to northeast Tunisia (Bons \& Geniez, 1996). Individuals spend all their lives buried in sandy soils, which lay below leaf litter, and can be commonly found under rocks (Civantos, Martín \& López, 2003; Martín, López \& García, 2013a). Interestingly, this amphisbaenian is often found in potential stable 'family groups' (Martín et al., 2011a,b), where the same individuals can be relocated together under the same or nearby rocks on different days within the same season (J Martín, 2020, unpublished data). In contrast to the oviparous reproductive system of most amphisbaenian species (Gans, 1978; Andrade, Nascimento \& Abe, 2006), T. wiegmanni is viviparous and bears live young at the end of summer (Bons \& Saint Girons, 1963). After birth, in early autumn, juveniles are often found in close proximity to a pair of adults or at least one adult individual, usually a female (Martín et al., 2011a,b), and successive recaptures suggest that this association is often maintained for several months into the next season (J Martín, 2020, unpublished data). These observations strongly suggest that juveniles might remain with their parents until they are older and, therefore, that some long-term parentoffspring association might occur (Martín et al., 2011a). These simple suggested forms of parent-offspring associations are similar to those identified for other viviparous lizard species, including those that live in stable family groups (e.g., Gardner et al., 2016; Halliwell et al., 2017). However, the importance of these social aggregations in this amphisbaenian and whether and how social recognition occurs are unknown.

Amphisbaenians have conspicuous morphological and functional adaptations to a fossorial life, such as reduced vision, elongated body and loss of limbs (Gans, 1974, 1978, 2005; Navas et al., 2004). However, these adaptations constrain many aspects of their ecology. The 
85

ecological demands of the fossorial underground environment and the responses of amphisbaenians are often very different from those of terrestrial epigeal reptiles that live over the ground surface (e.g., Papenfuss, 1982; Martín, López \& Salvador, 1990, 1991; Colli \& Zamboni, 1999; Webb et al., 2000). The detection and identification of conspecifics is one of the major ecological problems of the fossorial environment. Amphisbaenians have only rudimentary vision and the utility of visual cues is clearly limited underground (Gans, 1978). Thus, chemoreception may play an important function in detecting and identifying conspecifics, as it occurs in many squamate reptiles (Mason \& Parker, 2010; Martín \& López, 2011). The amphisbaenian Blanus cinereus uses chemical cues in conspecific and sex discrimination and in self-recognition (Copper, López \& Salvador, 1994; López, Cooper \& Salvador., 1997; López \& Martín, 2009), and this species is thought to be able to scent-mark and identify its own home range (López, Martín \& Barbosa, 2000). Similarly, both male and female adult T. wiegmanni can discriminate the scent of an adult individual with which they had formed a pair bond from an unfamiliar individual of the same sex as the partner, and males, but not females, have self-recognition abilities (Martín et al., 2020). We hypothesized that similar chemosensory abilities could allow the unexplored possibility of kin-recognition, and, therefore, that conspecific chemical cues may be very important in the formation and maintenance of stable family groups in fossorial animals. In this paper, we tested the ability of $T$. wiegmanni amphisbaenians to detect and discriminate by using chemical cues alone between familiar (likely related) individuals that were found together forming potential stable family groups (i.e. kin-recognition) and unfamiliar (likely unrelated) individuals. We specifically examined: a) whether adult amphisbaenians were able to recognize the juveniles that were found in their social 'family' group, which we are assuming are their offspring, against other unfamiliar juveniles, and b) whether juvenile 
108

109

110

111

112

113

114

115

116

117

118

119

120

121

122

123

124

125

amphisbaenians were able to recognize and discriminate between adult males and females, and to discriminate between the adults found in their social groups, which very likely could be their parents, and other unfamiliar adult individuals. We discuss how chemosensory discrimination of conspecifics may contribute to the formation of social relationships in fossorial animals.

\section{MATERIALS AND METHODS}

\section{Study site and study animals}

We conducted field work at the Chafarinas Islands (Spain) during April. This is a small volcanic archipelago located in the southwestern area of the Mediterranean Sea $\left(35^{\circ} 11^{\prime} \mathrm{N}, 2^{\circ} 25^{\prime} \mathrm{W}\right), 4.6$

$\mathrm{km}$ off of the northern Moroccan coast (Ras el Ma, Morocco) (Martín et al., 2011b,c). The climate is Mediterranean, dry and warm, and vegetation consists of bushes adapted to salinity and drought (Genus Suaeda, Salsola, Lycium and Atriplex). Populations of the amphisbaenian T. wiegmanni are very large in these islands (Martín et al., 2011c).

We followed different routes between 07:00 and 18:00 (GMT) and lifted most rocks found as amphisbaenians were found active under these rocks (López, Civantos \& Martín, 2002). When we found a possible familiar group of amphisbaenians (i.e., two adults, male and female, and one juvenile), we captured all individuals by hand. We used a metallic ruler to measure snout-to-vent length $(\mathrm{SVL}$, adults: mean $\pm \mathrm{SE}=148 \pm 4 \mathrm{~mm}$; juveniles: mean $\pm \mathrm{SE}=85 \pm 2$ $\mathrm{mm})$ We examined cloacas carefully and everted the hemipenes of males to determine sexes of adults. In all cases that two adults were found together under the same rock they were a male and a female. Juveniles, according to their body size, were individuals born at the end of the previous summer (see Bons \& Saint Girons, 1963; Martin et al., 2011b, 2012). Juveniles could not be sexed with reliability. Groups made up $24 \%$ of records, and single adults were not collected. 
We followed recommended procedures for the transport of live reptiles $(A S I H, 2004)$ to transport amphisbaenians to the laboratory. Family groups were kept together in separate plastic boxes with sand from the capture area. The same day after starting the journey, we housed amphisbaenians at "El Ventorrillo" Field Station (Navacerrada, central Spain). Individuals found in a group in the field were kept together in the same indoor plastic terrarium $(40 \times 30 \times 30 \mathrm{~cm})$, one for each group, throughout the whole experiment. Each terrarium had a loose coconut fiber substrate $(5 \mathrm{~cm}$ depth) and a flat tile $(20 \times 20 \mathrm{~cm})$ on the substrate surface to allow amphisbaenians to forage and thermoregulate under it (López, Salvador \& Martín, 1998; López, Civantos \& Martín, 2002). Amphisbaenians could attain an optimal body temperature by thigmothermy with the substrate warmed by a heating cable placed below the terraria, connected to a thermostat (Gatten \& McClung, 1981; López, Civantos \& Martín, 2002). The room was only illuminated with natural sunlight entering through large windows, so that the photoperiod was that of the region, although amphisbaenians spent all the time buried underground. We fed amphisbaenians three times per week mealworm larvae and pupae, snails and freshly pre-killed crickets, dusted with a multivitamin powder (Goetz, 2005; Martín et al., 2013b). We placed these prey under the tiles where amphisbaenians readily ate within a few hours. We moistened the substrate with a water spray frequently to avoid desiccation and to provide drinking water. All the individual amphisbaenians were healthy and monthly checks showed that they maintained or increased their original body mass.

Field study and capture of amphisbaenians were approved by the Spanish "Dirección General de Calidad y Evaluación Ambiental y Medio Natural" of the "Ministerio de Agricultura, Alimentación y Medio Ambiente" (number 12706). Research procedures were approved by the 
153 "Comisión Ética de Experimentación Animal (CEEA)" of the Museo Nacional de Ciencias 154 Naturales, CSIC.

155

156

157

158

159

160

161

162

163

164

165

166

167

168

169

170

171

172

173

174

175

\section{Chemosensory tests}

In June, we designed an experiment in the laboratory to estimate detection and discrimination of conspecific chemical cues by $T$. wiegmanni amphisbaenians. For this, we used measures of tongue-flick (TF) behavior in response to chemical stimuli presented on cotton swabs. This swab test provides a rapid and reliable bioassay of the ability of reptiles to respond differentially to biologically relevant scent stimuli (Cooper \& Burghardt, 1990; Cooper, 1994, 1998). This is based on that tongue-flicking behavior functions to sample chemicals for vomerolfactory analysis (Halpern, 1992). The existence of a correlation between elevated TF rates and vomeronasal organ use, and the necessity of an intact vomeronasal system for normal TF responses to scents have been experimentally tested (Graves \& Halpern, 1990; Halpern, 1992).

It is assumed that an increase in TF rates in response to a scent stimulus, with respect to the basal TF rates, indicates detection of that scent, and that differential TF rates to different chemical stimuli indicate discrimination of the different stimuli (Cooper \& Burghardt, 1990; Cooper, 1994, 1998; Martín et al., 2020). We compared TF rates of amphisbaenians in response to scents of different types of conspecifics and we also measured responses to distilled water as an inodorous scent control to gauge baseline TF rates in the experimental setup (Cooper \& Burghardt, 1990).

Because the groups of amphisbaenians used in this study were found at well separated field sites (more than $50 \mathrm{~m}$ between the nearest locations) and amphisbaenians have a low dispersal ability underground (J Martín, 2020, unpublished data), we assumed that individuals of 
176

177

178

180

181

182

183

each group had not had previous contact with individuals from other groups and were considered as unfamiliar individuals, whereas individuals within each group were considered as familiar individuals.

We designed a first experiment to test whether adult amphisbaenians display juvenile recognition (i.e., offspring recognition). We tested the responses of adult male $(n=10)$ and female ( $n=10)$ amphisbaenians to a) water (control), and scents of $b$ ) an unfamiliar juvenile that had never been in contact with the responding amphisbaenian and c) the familiar juvenile that was originally found in the field with the responding adult amphisbaenian (i.e., its potential offspring) and that shared its terrarium during all the study.

In a second experiment, we tested for sex and familiar recognition of adults by juvenile amphisbaenians (i.e., discrimination of adult males and females and recognition of adult members of their groups that might be their potential parents). We examined the responses of juveniles $(n=14)$ to a) water (control), and scents of four classes of adult amphisbaenians: b) the familiar male and c) the familiar female that were originally found in the field together with the juvenile and that shared its terrarium during the study, and d) an unfamiliar male and e) an unfamiliar female that had never been in contact with the juvenile.

To prepare the scent stimuli, we dipped the cotton tip $(1 \mathrm{~cm})$ of a wooden applicator $(10$ $\mathrm{cm}$ ) in deionized water and then rolled the moistened cotton over the cloaca of the donor amphisbaenian. Each individual amphisbaenian was used as donor of scent in two occasions in different days (as familiar or unfamiliar individual). Because, we tested in two different experiments the responses of adult to juvenile scent and vice versa, donor individuals had enough time to recover from any possible perturbation of this handling before being used as responding individuals.. 
Before starting the experiment, we gently took the responding amphisbaenian from its home terrarium and placed it in a clean testing cage $(20 \times 15 \mathrm{~cm})$ that contained a very shallow and loose clean substrate of coconut fiber $(0.5 \mathrm{~cm}$ depth $)$. We left the animal there for $15 \mathrm{~min}$ for acclimation to the new cage before undertaken the tests. This procedure allowed us to observe the amphisbaenian responses while they were semi-buried and behaving normally, as when they were completely buried in their terraria (i.e., without showing any signs of stress such as rapid escape locomotion or defensive behavior typically observed when amphisbaenians were brought above the surface). We made observations under a red light in the partially darkened laboratory to avoid disturbing amphisbaenians. Since chemoreceptive responses in reptiles can depend on temperature (Van Damme et al., 1990), we maintained air temperature in the laboratory at $22{ }^{\circ} \mathrm{C}$, close to the preferred temperature of T. wiegmanni (Gatten \& McClung, 1981; López, Civantos \& Martín, 2002). All animals had been acclimatized to laboratory conditions and experimenter's presence for at least two months before testing.

In each trial, the same experimenter (PL) in all cases, who was blind to the treatments, slowly moved the cotton swab to a position $2 \mathrm{~cm}$ anterior to the snout of the amphisbaenian, previously placed within the testing cage, and recorded the number of TF directed to the swab for $60 \mathrm{~s}$ beginning with the first TF. Amphisbaenians responded to the scent stimuli and directed TFs to the swab in all treatments and tests. We predicted that, if amphisbaenians had the ability to detect conspecifics using chemosensory communication, then TF rates to conspecific scents should be greater than to the control water. Differential TF rates to the different categories of conspecifics would indicate discrimination of these categories.

Each individual was tested with one single stimulus per day, and in subsequent days it was tested with the rest of treatments. Each cotton swab with a scent stimulus was used once in a 
222 single test of an individual, and then thrown away and a new one used for the next focal animal. 223 Order of presentation of the stimuli was randomized. We conducted trials between $1100 \mathrm{~h}$ and $2241500 \mathrm{~h}(\mathrm{GMT})$ when the amphisbaenians were fully active. After the tests, we immediately 225 returned each amphisbaenian to its home terrarium. To remove any chemical from the used 226 testing cage, we thoroughly rinsed it with clean water and soap and left it to dry outdoor before 227 being used in another test with a new coconut fiber substrate. We used several identical cages for 228 different tests.

Data analyses

231 232

233

234 235 236 237

To test for differential chemosensory responses of amphisbaenians to the different chemical conspecific stimuli, we used repeated measures General Lineal Models (GLMs) to test for differences in the numbers of TFs (dependent variable) among 'treatments' (water and the different conspecific scents) as a repeated measures factor. In the first experiment, we also included in the model the sex of the responding adult amphisbaenian as a fixed factor, and the interaction of sex with treatment. Residuals of the models fulfilled the normality and homoscedasticity assumptions after log-transformation of the numbers of TFs (tested with Shapiro-Wilk's and Hartley's Fmax tests). We used post-hoc Tukey's tests for comparisons of TF rates among treatments to test for discrimination of control water and the different conspecific chemical stimuli. 


\section{RESULTS}

243 Juvenile recognition by adult amphisbaenians

244 There were significant differences in TF rates of adult amphisbaenians among scent treatments 245 (repeated measures GLM, $\mathrm{F}_{2,36}=52.70, p<0.0001$ ) but there were no significant differences in 246 overall TF rates between sexes $\left(\mathrm{F}_{1,18}=0.23, p=0.64\right)$ and the interaction between treatment and

247 248

249 250

251

252 253 sex was significant $\left(\mathrm{F}_{2,36}=5.47, p=0.0084\right.$; Fig. 1).

Both males and females had significantly higher TF rates to cotton swabs bearing any of the juvenile stimuli than to the blank cotton swabs with water (Tukey's tests, $p<0.0003$ in all cases). In males, there were no significant differences between TF rates to the scent of the familiar or an unfamiliar juvenile $(p=0.99)$, while in females, the scent of familiar juveniles elicited higher TF rates than the scent of unfamiliar juveniles $(p<0.05$; Fig. 1$)$.

Additionally, the range of TFs responses to scent of familiar juveniles was greater in males than in females (Fig. 1), and while all individual females showed higher responses to the familiar than to the unfamiliar juvenile, only $50 \%$ of males showed higher responses to the familiar juvenile.

\section{Responses of juvenile amphisbaenians to adult scent}

There were significant differences in $\mathrm{TF}$ rates of juvenile amphisbaenians among scent treatments (repeated measures GLM, $\mathrm{F}_{4,52}=24.49, p<0.0001$; Fig. 2). Post-hoc tests showed that $\mathrm{TF}$ rates of juveniles to water were significantly lower than to any conspecific stimuli (Tukey's tests, $p<0.0006$ in all cases), showing that all conspecific scents were detected. Responses to scent of an unfamiliar male were significantly lower than to the familiar male ( $p<$ $0.03)$ and familiar $(p=0.0036)$ or unfamiliar female $(p=0.0085)$. The TF rates to the familiar 
265 male, however, did not significantly differ of TF rates to the familiar $(p=0.95)$ or unfamiliar

266 female ( $p=0.99)$, which did not differ ( $p=0.99$; Fig. 2).

267

268

269

270

271

272

273

274

275

276

\section{DISCUSSION}

Our results are consistent with the hypothesis that $T$. wiegmanni amphisbaenians are able to detect and to discriminate among several categories of conspecifics using chemical cues alone. Specifically, the results of this study strongly suggest that adult female amphisbaenians are capable of, presumed, offspring recognition. Moreover, juvenile amphisbaenians are able to partly recognize the adults with which they have been associated in the long-term, which probably are their parents. However, adult males did not discriminate between familiar and unfamiliar juveniles, and juveniles did not discriminate between familiar and unfamiliar adult females.

With respect to the discrimination of scents of juveniles by adult $T$. wiegmanni amphisbaenians, there were clear intersexual differences; adult males detected and discriminated the juvenile scent from water, but these males did not discriminate between an unfamiliar juvenile and the familiar juvenile that was found with the male in the field and that shared his terrarium in the experimental situation. This result is very interesting because in many animal species, males through distinct sensory pathways can discriminate their own offspring (familiar) from non-related offspring (unfamiliar) and with this strategy they mediate protective or infanticide behaviors (Waldman, 1988; Elwood, 1991, 1992; While, Uller \& Wapstra, 2009). It is likely that male $T$. wiegmanni may be able to discriminate the scent of familiar juveniles from adult individuals, but there might not be an adaptive function to discriminate their offspring if there are no significant benefits for their fitness (e.g. Beecher, 1991; Kempenaers \& Sheldon, 
1996). Likely adult male T. wiegmanni would not commit infanticide for this reason, but neither offer protection to their offspring. Nevertheless, alternatively, it could be possible that there was a confounding statistical effect when considering the response of all males on average due to the mixed chemosensory responses of different individual males (i.e., some individuals but not others elicited higher responses to familiar than to unfamiliar juveniles). These results might lead to speculate that the responses were different because only some individual males, but not others, were actually the fathers of the familiar juvenile tested, and, thus, perhaps males might be able to recognize their offspring. More experiments where the actual paternity relationships were known are clearly needed to test this hypothesis.

In contrast, adult females discriminated and showed higher chemosensory responses to scents of the familiar juvenile in comparison with an unfamiliar juvenile. Offspring chemical recognition by females has been reported in some lizard species (Main \& Bull, 1996; O'Connor \& Shine, 2006; Head et al., 2008). This recognition in animals without direct parental care may be important to avoid interference competition such as reducing parent aggression and seeking to establish territories near their kin (Bull \& Baghurst, 1998; Lena \& de Fraipont, 1998; O'Connor \& Shine, 2004; Head et al., 2008). Juveniles may benefit from staying with their mothers; for example, in some skinks, females show high levels of conspecific aggression during the postpartum period that may avoid infanticide by other individuals, such that offspring from more aggressive females have higher survival (O’Connor \& Shine, 2004; Sinn, While \& Wapstra, 2008). These simple recognition mechanisms may be the first evolutionary steps towards more complex forms of parental care and more complex forms of family life.

These intersexual differences in offspring recognition might be explained by the different probabilities of genetic relatedness between juveniles and the adult male or female found 
311 together, which could be linked to the viviparous reproductive system of this amphisbaenian

312 (Bons \& Saint Girons, 1963). Thus, it seems very likely that the juvenile found associated with a

313 female was her offspring, since the association could have begun with the birth of the juvenile. A

314 female might, therefore, suffer a selective pressure to recognize her offspring from other

315 juveniles, especially if females provided some kind of parental care or protection to their

316 offspring (Neff, 2003). In contrast, a male found close to a juvenile, may or may not be the actual

317 father since mating occurs in spring and juveniles were born at the end of summer and the rates

318 of multiple paternities and the potential for factors like long-term sperm storage remain unknown

319 for this species. In this case, there is the potential that males do not provide active protection to

320 juveniles, even if they were found together. Therefore, males would not be selected to recognize

321 their offspring, even if the familiar (or actually related) juvenile was found often in contact with

322 the male. In fact, although we focused this study on groups formed by a male, a female, and a

323 juvenile, it is more frequent to find in the field a female alone with a juvenile (Martín et al.,

$3242011 a)$

Juvenile T. wiegmanni amphisbaenians clearly detected scents of adults with respect to

the blank control (water) and showed higher chemosensory responses to either the familiar or an unfamiliar female, but also to the familiar male, while the scent of an unfamiliar male was also detected but received lower responses. Recognition by association occurs when an animal learns the particular distinctive signals of familiar individuals around it and perceive these as kin (O’Connor \& Shine, 2006). If juveniles received some benefits from being associated to their parents (or just to the adults in the group, even if they were not their actual parents), juveniles should be able to detect and discriminate their scent in order to identify and follow them in the underground environment. This behavior would confer substantial fitness advantages in juveniles 
334 allowing them to share the territory and other resources of familiar and experienced adults in an

environment where resources are perhaps limited.

The lack of discrimination of some categories of adults may reflect that juveniles show a generalized response to any nearby conspecific adult, which might suggest that some learning or previous experience with different adult individuals is required for a more accurate individual identification (Tang-Martinez, 2001; Frommen, Luz \& Bakker, 2007). This may be explained because juveniles, which have very limited movement rates, would only rarely find adults other than those in their respective social groups. Incomplete experience (recognition by association) with the scent of adult individuals might explain the observed higher responses to any female, similar to those to the familiar male, and the lowest responses to the unfamiliar male. Juveniles might not have a selective pressure to discriminate between individual females because, as they are viviparous, offspring are always going to be associated with their mother upon birth. Also, it is possible that there is low interindividual variation in the chemical scent of females which inhibits individual recognition of particular females. In contrast, chemical differences between the scent of different males might be higher, providing an easier identification of the familiar male. Similarly, in some lizards and other amphisbaenians, males have a higher number, diversity and interindividual variability of lipophilic compounds in femoral or precloacal secretions than females (García-Roa et al., 2014; Martín \& López, 2006). Nevertheless, in T. wiegmanni, both male and female adults are capable of discriminating between cloacal scent of familiar and unfamiliar partners (Martín et al., 2020), suggesting that interindividual chemical signatures are different enough as to allow discrimination, at least after some learning. There may be stronger selection for juveniles to recognize different individual males because the male found in a group might or might not be the father of the juvenile. Moreover, if adult males were 
capable of discriminating between their offspring and other juveniles, adult males might be more territorial and aggressive towards unrelated juveniles, and, then, these juveniles should be able to detect and avoid unfamiliar males.

Many studies across a host of different species of lizards and snakes have used tongueflick behavior as an indirect way of measuring vomerolfaction (Cooper \& Burghardt, 1990; Halpern, 1992 Cooper, 1994, 1998). These studies assume that differences in TF rates between stimuli indicate discrimination of a scent, but also that identification may occur with only a few TFs, being a further increase in TFs a reflect of a 'higher interest' for a given scent. Therefore, the differences in TF rates of T. wiegmanni observed in our experiment can confidently be considered as chemosensory recognition and discrimination of different scents. The lack of differences observed between some stimuli, however, indicated that both scents elicited a similar interest, although not necessarily in all cases, that they were not recognized as different scents. Alternatively, the cloacal chemical cues used in our study might not provide complete information and amphisbaenians may need additional cues, or additional learning, to achieve a complete identification of conspecifics. If this is the case, further experiments examining other stimuli and other behavioral responses may be needed to determine the extent of the conspecific discrimination abilities of amphisbaenians.

Although we lack data of the actual paternity and genetic relatedness between the adults and the juvenile amphisbaenians of each group that we found together in the field, our results may suggest that kin-recognition occurs in at least adult female $T$. wiegmanni. The conditions of the fossorial environment may explain the observed low dispersal ability and high site fidelity of individual T. wiegmanni amphisbaenians (J. Martín, 2020, unpublished data). Therefore, it is very likely that, because of the viviparous reproduction, the juvenile and at least the female 
380 found together were genetically related. Further studies should consider a design to compare the responses of truly genetically related adults and juveniles with those of individuals that are unrelated but familiar because they are experimentally placed together. Indeed, such an experimental design would also reveal the mechanism for which recognition of related individuals can occur. Kin-recognition may occur by 'association', when animals learn to recognize the individual signals of other animals that live together, and that are thereafter considered as kin, or by 'phenotype matching', when animals use a reference phenotype (either self or kin) against which other individuals are compared (Halpin, 1991; Tang-Martinez, 2001). In lizards, both mechanisms have been found (Bull et al., 2001; O'Connor \& Shine, 2006), yet for fossorial amphisbaenians, with low mobility, it might be more likely that recognition by association is occurring, if the probability of finding unrelated individuals in the group is low. This hypothesis remains to be tested and future studies are needed.

\section{CONCLUSIONS}

Our findings suggest that chemosensory kin-recognition may allow amphisbaenians to recognize offspring and tolerate relatives or familiar individuals, to maintain stable family associations of, at least, mother and offspring, to reduce kin competition and intraspecific aggression. Our findings give insight into an early stage in the evolution of kin-recognition and the establishment of familiar groups as they suggest that individual amphisbaenians may benefit from being capable of chemosensory recognition of conspecifics. There could be initial selection for chemosensory detection of familiar individuals, but animals at an early stage of familiar grouping may not have evolved the means to assess the relatedness of conspecifics. Only as the system becomes more efficient might detection of related individuals benefits accrue, and 
403 selection might operate on individuals to perceive this and to maintain long-term family groups.

404 Future studies should examine the mechanisms for which recognition occurs, how social associations are maintained and the benefits of these social aggregations for juvenile and adult amphisbaenians in the fossorial environment.

\section{ACKNOWLEDGEMENTS}

We thank G. Alexander, K. Strickland, and an anonymous reviewer for their helpful comments. We also thank the field station of the "Refugio Nacional de Caza de las Islas Chafarinas" for logistical support and "El Ventorrillo" MNCN Field Station for use of their facilities. We thank J.I. Montoya, J. Díaz, G. Martínez, A. Sanz, F. López, A. Ruiz, and J. Zapata for support and friendship in the Islands.

\section{REFERENCES}

Andrade DV, Nascimento LB, Abe AS. 2006. Habits hidden underground: a review on the reproduction of the Amphisbaenia with notes on four neotropical species. Amphibia-Reptilia 27:207-217.

ASIH. 2004. Guidelines for use of live Amphibians and Reptiles in field and laboratory research. 2nd edn. Herpetological Animal Care and Use Committee (HACC) of the Lawrence, Kansas: American Society of Ichthyologists and Herpetologists.

Beecher MD. 1991. Successes and failures of parent-offspring recognition in animals. In: Hepper PG, ed. Kin recognition. Cambridge: Cambridge University Press, 95-124.

Bons J, Geniez P. 1996. Amphibians and Reptiles of Morocco. Madrid, Spain: Asociación Herpetológica Español,.

Bons J, Saint Girons H. 1963. Ecologie et cycle sexuel des amphisbeniens du Maroc. Bulletin de la Société des Sciences Naturelles et Physiques du Maroc 43:117-158 
427

Bull CM, Baghurst BC. 1998. Home range overlap of mothers and their offspring in the sleepy lizard, Tiliqua rugosa. Behavioral Ecology and Sociobiology 42: 357-362.

Bull CM, Doherty M, Schulze LR, Pamula Y. 1994. Recognition of offspring by females of the Australian skink, Tiliqua rugosa. Journal of Herpetology 28:117-120.

Bull CM, Griffin CL, Lanham EJ, Johnston GR. 2000. Recognition of pheromones from group members in a gregarious lizard, Egernia stokesii. Journal of Herpetology 34:92-99.

Bull CM, Griffin CL, Bonnett M, Gardner MG, Cooper SJ. 2001. Discrimination between related and unrelated individuals in the Australian lizard Egernia striolata. Behavioral Ecology and Sociobiology 50:173-179.

Chapple D. 2003. The evolution of complex sociality in reptiles: a review of ecology, life-history and behavior in the Australian scincid genus Egernia. Herpetological Monographs 17:145180.

Civantos E, Martín J, López P. 2003. Fossorial life constrains microhabitat selection of the amphisbaenian Trogonophis wiegmanni. Canadian Journal of Zoology 81:1839-1844.

Colli GR, Zamboni DS. 1999. Ecology of the worm-lizard Amphisbaena alba in the cerrado of central Brazil. Copeia 1999:733-742.

Cooper WE. 1994. Chemical discrimination by tongue-flicking in lizards: a review with hypotheses on its origin and its ecological and phylogenetic relationships. Journal of Chemical Ecology 20:439-487.

Cooper WE. 1998. Evaluation of swab and related tests as a bioassay for assessing responses by squamate reptiles to chemical stimuli. Journal of Chemical Ecology 24:841-866.

Cooper WE, Burghardt GM. 1990. A comparative analysis of scoring methods for chemical discrimination of prey by squamate reptiles. Journal of Chemical Ecology 16:45-65. 
450 Cooper WE, López P, Salvador A. 1994. Pheromone detection by an amphisbaenian. Animal 451 Behaviour 47:1401-1411.

452 Clutton-Brock TH. 1991. The evolution of parental care. Princeton, USA: Princeton University $453 \quad$ Press.

454

Duffield G, Bull CM. 2002. Stable social aggregations in an Australian lizard, Egernia stokesii. Naturwissenschaften 89:424-427.

Elwood RW. 1991. Parental states as mechanisms for kinship recognition and deception about relatedness. In: Hepper PG, ed. Kin recognition. Cambridge: Cambridge University Press, 289-307.

Elwood RW. 1992. Pup-cannibalism in rodents: causes and con-sequences. In: Elgar ME, Crespi BJ, eds. Cannibalism: ecology and evolution among diverse taxa. Oxford: Oxford University Press, 299-322.

Frommen JG, Luz C, Bakker T. 2007. Kin discrimination in sticklebacks is mediated by social learning rather than innate recognition. Ethology 113:276-282.

Gans C. 1974. Biomechanics: an approach to vertebrate biology. Philadelphia, USA: Lippincot,

Gans C. 1978. The characteristics and affinities of the Amphisbaenia. Transactions of the Zoological Society of London 34:347-416.

Gans C. 2005. Checklist and bibliography of the amphisbaenia of the World. Bulletin of the American Museum of Natural History 280:1-130.

García-Roa R, Ferreira S, López P, Martín J. 2016. Genders matters: Sexual differences in chemical signals of Liolaemus wiegmannii lizards (Iguania, Liolaemidae). Biochemical Systematics and Ecology 69:108-114. 
472 Gardner MG, Pearson SK, Johnston GR, Schwarz MP. 2016. Group living in squamate reptiles: a review of evidence for stable aggregations. Biological Reviews 91:925-936.

Gatten RE, McClung RM. 1981. Thermal selection by an amphisbaenian, Trogonophis wiegmanni. Journal of Thermal Biology 6:49-51.

Goetz M. 2005. Zur haltung und nachzucht der schachbrett-doppelschleiche Trogonophis wiegmanni Kaup, 1830 (Squamata: Amphisbaenia: Trogonophidae). Sauria 27:27-31.

Graves BM, Halpern M. 1990. Roles of vomeronasal chemoreception in tongue flicking, exploratory and feeding behaviour of the lizard, Chalcides ocellatus. Animal Behaviour 39:692-698.

Halliwell B, Uller T, Holland BR, While GF. 2017. Live bearing promotes the evolution of sociality in reptiles. Nature Communications 8:2030.

Halpern M. 1992. Nasal chemical senses in reptiles: structure and function, In: Gans C, Crews D, eds. Biology of the Reptilia, Vol. 18, Brain, hormones, and behavior. Chicago: University of Chicago Press, 423-523.

Halpin Z. 1991. Kin recognition cues of vertebrates. In: Hepper PG, ed. Kin recognition. Cambridge: Cambridge University Press, 220-258.

Head ML, Doughty P, Blomberg SP, Keogh JS. 2008. Chemical mediation of reciprocal motheroffspring recognition in the southern water skink (Eulamprus heatwolei). Austral Ecology $33: 20-28$.

Henderson RW, Powell R, Martín J, López P. 2016. Sampling techniques for arboreal and fossorial reptiles, In: Dodd Jr CK, ed. Reptile ecology and conservation. A handbook of techniques. Oxford: Oxford Univ. Press, 139-153. 
494 Kempenaers B, Sheldon BC. 1996. Why do male birds not discriminate between their own and extra-pair offspring?. Animal Behaviour 51:1165-1173.

Langkilde T, O’Connor D, Shine R. 2007. Benefits of parental care: do juvenile lizards obtain better quality habitat by remaining with their parents? Austral Ecology 32:950-954.

Lena JP, de Fraipont M. 1998. Kin recognition in the common lizard. Behavioral Ecology and Sociobiology 42:341-348.

López P, Martín J. 2005. Intersexual differences in chemical composition of precloacal gland secretions of the amphisbaenian, Blanus cinereus. Journal of Chemical Ecology 31:29132921.

López P, Martín J. 2009. Potential chemosignals associated with male identity in the amphisbaenian Blanus cinereus. Chemical Senses 34:479-486.

López P, Cooper WE, Salvador A. 1997. Discrimination of self from other males by chemosensory cues in the amphisbaenian (Blanus cinereus). Journal of Comparative Psychology 111:105-109.

López P, Salvador A, Martín J. 1998. Soil temperatures, rock selection and the thermal ecology of the amphisbaenian reptile Blanus cinereus. Canadian Journal of Zoology 76:673-679.

López P, Martín J, Barbosa A. 2000. Site familiarity affects antipredatory behavior of the amphisbaenian Blanus cinereus. Canadian Journal of Zoology 78:2142-2146

López P, Civantos E, Martín J. 2002. Body temperature regulation in the amphisbaenian Trogonophis wiegmanni. Canadian Journal of Zoology 80:42-47.

Main AR, Bull CM. 1996. Mother-offspring recognition in two Australian lizards, Tiliqua rugosa and Egernia stokesii. Animal Behaviour 52:193-200. 
516 Martín J, López P. 2011. Pheromones and reproduction in Reptiles. In: Norris DO, Lopez KH, 517 eds. Hormones and reproduction of vertebrates, vol 3. Reptiles. San Diego, California:

$518 \quad$ Academic Press, 141-167.

519 Martín J, López P, Salvador A. 1990. Field body temperatures of the amphisbaenid lizard Blanus $520 \quad$ cinereus. Amphibia-Reptilia 11:87-96.

521

522

523

524

525

526

527

Martín J, López P, Salvador A. 1991. Microhabitat selection of the amphisbaenian Blanus cinereus. Copeia 1991:1142-1146.

Martín J, Polo-Cavia N, Gonzalo A, López P, Civantos E. 2011a. Social aggregation behaviour in the North African amphisbaenian Trogonophis wiegmanni. African Journal of Herpetology 60:171-176

Martín J, Polo-Cavia N, Gonzalo A, López P, Civantos E. 2011b. Structure of a population of the amphisbaenian Trogonophis wiegmanni in North Africa. Herpetologica 67:250-257.

Martín J, Polo-Cavia N, Gonzalo A, López P, Civantos E. 2011c. Distribución, abundancia y conservación de la culebrilla mora (Trogonophis wiegmanni) en las Islas Chafarinas. Boletín de la Asociación Herpetológica Española 22:107-112.

Martín J, Polo-Cavia N, Gonzalo A, López P, Civantos E. 2012. Sexual dimorphism in the North African amphisbaenian Trogonophis wiegmanni. Journal of Herpetology 46:338-341.

Martín J, López P, García LV. 2013. Soil characteristics determine microhabitat selection of the fossorial amphisbaenian Trogonophis wiegmanni. Journal of Zoology 290:265-272.

Martín J, Ortega J, López P, Pérez-Cembranos A, Pérez-Mellado V. 2013b. Fossorial life does not constrain diet selection in the amphisbaenian Trogonophis wiegmanni. Journal of Zoology 291:226-233. 
538 Martín J, Raya-García E, Ortega J, López P. 2020. How to maintain underground social 539 relationships? Chemosensory sex, partner and self recognition in a fossorial amphisbaenian. $540 \quad$ PlosOne 15(8):e0237188.

541 Mason RT, Parker MR. 2010. Social behavior and pheromonal communication in reptiles.

542 Journal of Comparative Physiology A 196:729-749

Navas CA, Antoniazzi MM, Carvalho JE, Chaui-Berlink JG, James RS, Jared C, Kohlsdorf T, Pai-Silva MD, Wilson RS. 2004. Morphological and physiological specialization for digging in amphisbaenians, an ancient lineage of fossorial vertebrates. Journal of Experimental Biology 207:2433-2441.

Neff BD. 2003. Decisions about parental care in response to perceived paternity. Nature 422:716-719.

O’Connor D, Shine R. 2003. Lizards in 'nuclear families': a novel reptilian social system in Egernia saxatilis (Scincidae). Molecular Ecology 12:743-752.

O’Connor D, Shine, R. 2004. Parental care protects against infanticide in the lizard Egernia saxatilis (Scincidae). Animal Behaviour 68:1361-1369.

O’Connor D, Shine, R. 2006. Kin discrimination in the social lizard Egernia saxatilis (Scincidae). Behavioral Ecology 17:206-211.

Papenfuss TJ. 1982. The ecology and systematics of the amphisbaenian genus Bipes. Occasional Papers of the Californian Academy of Sciences 136:1-42.

Sinn DL, While GM, Wapstra E. 2008. Maternal care in a social lizard: links between female aggression and offspring fitness. Animal Behaviour 76:1249-1257.1257

Tang-Martinez Z. 2001. The mechanisms of kin discrimination and the evolution of kin recognition in vertebrates: a critical reevaluation. Behavioral Processes 53:21-40. 
Van Damme R, Bauwens D, Vanderstighelen D, Verheyen RF. 1990. Responses of the lizard Lacerta vivipara to predator chemical cues: the effects of temperature. Animal Behaviour 40:298-305.

Waldman B. 1988. The ecology of kin recognition. Annual Review of Systematics and Ecology 19:543-571.

Webb JK, Shine R, Branch WR, Harlow PS. 2000. Life underground: food habits and reproductive biology of two amphisbaenian species from South Africa. Journal of Herpetology 34:510-516.

Werner DI, Baker EM, Gonzales EC, Sosa IR. 1987. Kinship recognition and grouping in hatchling green iguanas. Behavioral Ecology and Sociobiology 21:83-89.

While GM, Uller T, Wapstra E. 2009. Family conflict and the evolution of sociality in reptiles. Behavioral Ecology 20:245-250.

While GM, Gardner MG, Chapple DG, Whiting MJ. 2019. Stable social grouping in lizards. In: V Bels V, Russell A, eds. Behavior of lizards: evolutionary and mechanistic perspectives . Boca Raton, Florida: CRC Press, 321-339.

Whiting MJ, While GM. 2017. Sociality in lizards. In: Rubenstein DR, Abbot P, eds. Comparative social evolution. Cambridge: Cambridge University Press, 390-426. 


\section{Figure 1}

Responses of adult $T$. wiegmanni amphisbaenians to juvenile scent.

Box-whiskers plots for the number of directed tongue-flicks emitted by male (hatched boxes) and female (open boxes) adult amphisbaenians in $60 \mathrm{~s}$ in response to control water or chemical stimuli of familiar or unfamiliar juveniles presented on cotton swabs. Letters indicate statistically significant differences in post-hoc Tukey's tests between treatments. 


\section{Juvenile recognition by adults}

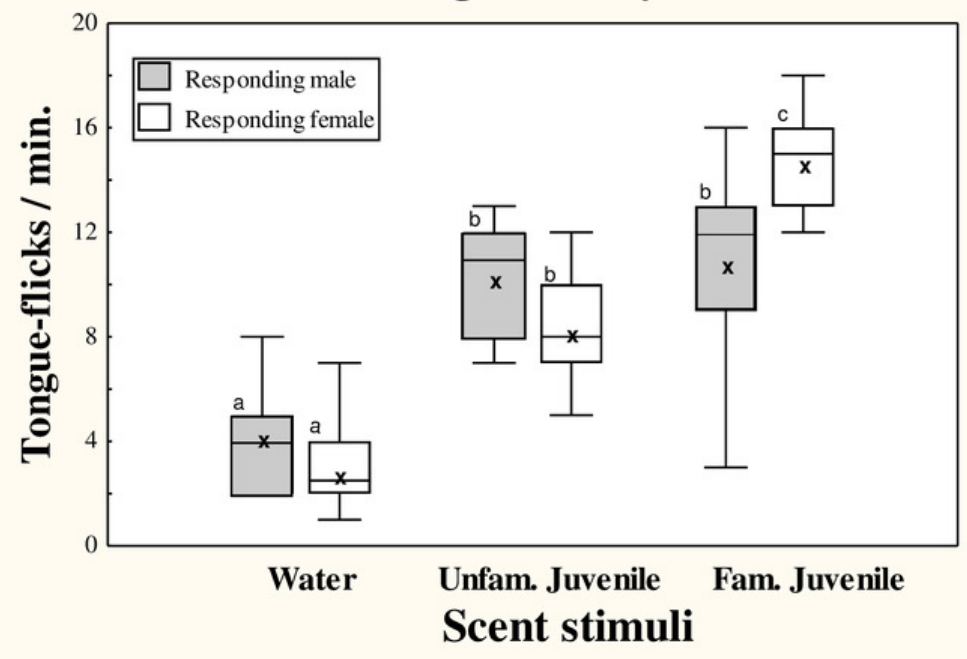


Figure 2

Responses of juvenile $T$. wiegmanni amphisbaenians to adult scent.

Box-whiskers plots for the number of directed tongue-flicks emitted by juvenile amphisbaenians in $60 \mathrm{~s}$ in response to control water or chemical stimuli of familiar or unfamiliar adults presented on cotton swabs. Letters indicate statistically significant differences in post-hoc Tukey's tests between treatments. 


\section{Adult recognition by juveniles}

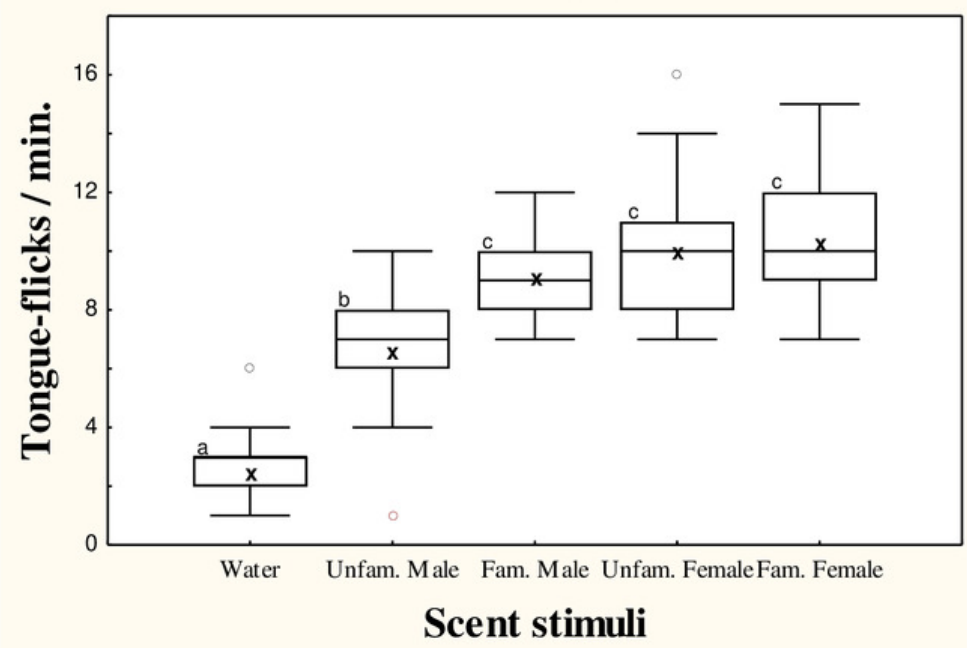

